\title{
A. Cervoni, Théophile Gautier devant la critique, 1830-72
}

Ida Merello

\section{(2) OpenEdition}

1 Journals

\section{Édition électronique}

URL : http://journals.openedition.org/studifrancesi/10704

DOI : 10.4000/studifrancesi. 10704

ISSN : 2421-5856

Éditeur

Rosenberg \& Sellier

\section{Édition imprimée}

Date de publication : 1 décembre 2017

Pagination : 579

ISSN : 0039-2944

\section{Référence électronique}

Ida Merello, « A. Cervoni, Théophile Gautier devant la critique, 1830-72 », Studi Francesi [En ligne], 183 (LXI | III) | 2017, mis en ligne le 01 février 2018, consulté le 24 janvier 2021. URL : http://

journals.openedition.org/studifrancesi/10704; DOI : https://doi.org/10.4000/studifrancesi.10704

Ce document a été généré automatiquement le 24 janvier 2021.

\section{(c) (i) (9)}

Studi Francesi è distribuita con Licenza Creative Commons Attribuzione - Non commerciale - Non opere derivate 4.0 Internazionale. 


\title{
A. Cervoni, Théophile Gautier devant la critique, 1830-72
}

\author{
Ida Merello
}

\section{RÉFÉRENCE}

AURÉLIA CERVONI, Théophile Gautier devant la critique, 1830-72, Paris, Classiques Garnier, 2016.

L'ouvrage constitue un travail désormais incontournable sur la réception des œuvres de Théophile Gautier, au fil de leur parution. Ce qui émerge n'est pas seulement l'histoire de la fortune critique de l'auteur, vue au microscope, mais une relecture du Romantisme, à travers l'éventail des positions critiques qui, au long des années, révèlent son évolution, entravée par la myopie de la censure aussi bien que par le poids du roman des mœurs, empêchant dès les années 1830 de bien évaluer une production anti réaliste. Les critiques portées contre certains détails de l'œuvre de Gautier, à commencer par Albertus, considéré comme outrageux à la morale, dessinent le panorama des rapports entre la société et l'art, et des engagements que celui-ci est censé assumer vu son rôle public. C'est pourquoi les Jeunes-France ne sont bien appréciés que par les artistes libertaires dont Gautier brosse la caricature, tandis que même les journaux philo-romantiques se rangent du côté du régime, et que les critiques professionnels y trouvent une confirmation de leur mépris du conte. L'A. explique très clairement comment le scandale suscité par Mlle de Maupin dérive de l'attitude de la presse contre Gautier des années 1833-1834, étant donné un panorama de production littéraire consacrée aux sujets politiques et sociaux, où l'autonomie de l'art semble avoir une valeur narcissique. L'A. rappelle que Victor Hugo, à qui l'on doit la définition de manifeste de l'art pour l'art à propos de Mlle de Maupin, ne signe pourtant pas son compte rendu, pour ne pas offrir son soutien auctorial à une vision qui apparaît comme élitaire. En fait, d'un côté il y a la littérature de régime, obligée d'être édifiante, de l'autre la production saint-simonienne, au service de l'ordre social: pour la liberté, il reste un espace très mince. Le rapprochement établi entre le jeune 
Gautier et le poète assassin sérial Lacenaire, dont le procès commence à la fin de 1835, rend parfaitement compte de l'hostilité que l'attitude libertaire et individualiste de Gautier a rencontrée. La parution de La Comédie de la mort a confirmé tous les préjugés contre le poète, qui aurait pu devenir à ce moment de sa carrière le premier des maudits, accusé d'immoralité et de décadence. Bien avant la Charogne de Baudelaire, le dialogue entre le Ver et la Trépassée indigne les honnêtes gens, qui crient à l'horreur de la décadence; ce qui permet d'ailleurs à Gautier de bien définir son idée là-dessus, renversant le préjugé ordinaire de corruption du goût dans celui de la maîtrise raffinée du style. Il n'arrive pourtant pas à gagner la faveur des critiques: aussi, l'ironie de Fortunio et du recueil Une larme du diable ne sont-elles pas mieux comprises, et l'on attribue à Gautier un matérialisme subversif, qui, plus tard, sera perçu comme antirépublicain. L'A. met en relief que Gautier ne se délivre de son image sulfureuse que grâce aux textes des ballets et aux récits de voyage, qui le transforment d'emblée dans un personnage en vue au cœur de la société. Voilà pourquoi le manque d'attention politique de Voyage en Espagne, où les aspects picturaux seuls sont pris en compte, et tout juste avant la révolution espagnole, est finalement apprécié comme l'une de ses caractéristiques positives.

2 L'A. montre ensuite les différentes attitudes de la critique face aux Grotesques, qui paraissent plus une interprétation partiale et passionnée qu'une étude objective, et constate la baisse de réputation de l'écrivain au moment de la parution du Roi Candaule à cause de son amour pour le monde classique. Gautier est attaqué comme conformiste, d'autant plus qu'il devient une institution de la Presse, tandis que sa Chronique hebdomadaire est souvent reprochée de platitude et de faiblesse de style.

Un point fort de l'analyse est l'attention au débat déclenché par la publication d'Emaux et Camées, qui fait accuser en même temps Gautier d'impassibilité et d'excès de raffinement décadent: l'A. entre dans le mérite du rapport entre Gautier et Baudelaire, en lisant la dédicace des Fleurs du mal au «Maître impeccable» comme la proclamation d'une impeccabilité artistique qui se soustrait à tout jugement moral. Une importante citation tirée du Journal des Goncourt où Gautier, par sa sensibilité et par ses choix poétiques, est présenté comme le poète de la modernité, permet de montrer son rôle charnière entre les deux moitiés du siècle. En effet le Capitaine Fracasse, malgré ceux qui n'y voyaient qu'un pastiche des Grotesques, est généralement salué comme le début d'une nouvelle école fondée sur le renouveau de la langue. Le livre se conclut par les épitaphes en l'honneur de Gautier et il est suivi d'une précieuse chronologie de tous les articles consacrés à Gautier de 1830 à 1872, et d'une bibliographie la plus complète possible. 